\title{
Incorporation of Fluorophore-Cholesterol Conjugates into Liposomal and Mycobacterial Membranes
}

\author{
Ashley N. Wercholuk, Jenna M. Thuman, Jordan L. Stanley, Andrew L. Sargent, Eric S. \\ Anderson,* and William E. Allen* \\ Departments of Chemistry and Biology, Science and Technology Building, East Carolina \\ University, Greenville, NC 27858-4353, USA
}

\begin{abstract}
Fluorescently-labeled steroids that emit intense blue light in nonpolar solvent $\left(\lambda_{\mathrm{em}}\right.$ $\left.\left(\mathrm{CH}_{2} \mathrm{Cl}_{2}\right) \approx 440 \mathrm{~nm}, \Phi_{\mathrm{F}}=0.70\right)$ were prepared by treating cholesteryl chloroformate with 4amino-1,8-naphthalimides. The lipid portion of the conjugates embeds into liposomal membrane bilayers in minutes, leaving the fluorophore exposed to the external aqueous environment. This causes a 40-nm red-shift in $\lambda_{\text {em }}$ and significant quenching. DFT optimizations predict the conjugates to be about $30 \AA$ long when fully extended, but rotation about the linker group can bring the compounds into an "L"-shape. Such a conformation would allow the cholesteryl anchor to remain parallel to the acyl chains of a membrane while the fluorescent group resides in the interfacial region, instead of extending beyond it. When incubated with Mycobacterium smegmatis mc2 155, a bacterial species known to use natural cholesterol, the labeled steroids support growth and can be found localized in the membrane fraction of the cells using HPLC. These findings demonstrate stable integration of fluorescent cholesterols into bacterial membranes in vivo, indicating that these compounds may be useful for evaluating cholesterol uptake in prokaryotic organisms.
\end{abstract}

Keywords: fluorescence; cholesterol trafficking; membrane transport; tuberculosis Corresponding author's contact information: 252-328-9779; allenwi@ecu.edu 


\section{Introduction}

Numerous species of bacteria extract cholesterol from the cells of their hosts. ${ }^{1}$ Mycobacterial species such as $M$. tuberculosis $(M t b)$ use the sterol as a primary source of carbon and energy during the latent stage of infection, ${ }^{2}$ catabolizing the tetracyclic core and the side-chain via multiple pathways. ${ }^{3}$ Initial import of cholesterol is performed by the Mce4 protein complex, which also recognizes other steroids with nonpolar alkyl groups present on the D-ring. ${ }^{4} \mathrm{~A}$ fuller understanding of mycobacterial utilization of such compounds could lead to new therapies for $M t b$ infection. Studies of cholesterol dynamics and trafficking are commonly carried out using fluorescence spectroscopy. For uptake in the mycobacterial system, the presence of a polar fluorescent group at $\mathrm{C} 22$ or $\mathrm{C} 25^{5}$ of the side-chain might interfere with the site(s) of Mce4 recognition. For this reason, the conjugates presented here are labeled far from the alkyl chain, at the 3-position of the A-ring, via a carbamate linker that is resistant toward non-enzymatic hydrolysis. ${ }^{6}$ Steroids with labels on ring A or B have been previously described, ${ }^{6 a, 7}$ but unlike those systems, the fluorescent unit in the present work was selected for its potential antimicrobial activity. We envisioned that such conjugates might serve one of two roles, depending on whether the toxicity of the fluorophore was retained in the conjugates: as reporters for following in vivo uptake/catabolism of cholesterol, or as "Trojan horse" antibiotics. ${ }^{8}$ Spectroscopic techniques as well as bacterial viability studies were employed to evaluate how the modified cholesterols localize in model membrane bilayers, and whether they are harmful to live cells. The strain $M$. smegmatis mc2 155 was chosen as the model for evaluation of our compounds, because of its demonstrated ability to take up cholesterol, and its relatively rapid growth.

\section{Results and discussion}




\subsection{Synthesis}

Two known 4-amino-1,8-naphthalimides ${ }^{9}$ (1, Scheme 1) were attached to cholesterol. The antibacterial properties of naphthalimides are well-established. ${ }^{10}$ Fluorophores like $\mathbf{1}$ are relatively compact (MW < 300) yet brightly luminescent (yellow-green) in organic solution, and are employed in a variety of sensing applications. ${ }^{11}$ Their $-\mathrm{NH}_{2}$ groups are part of an environmentally-sensitive electronic "push-pull" system. ${ }^{12}$ As such, nucleophilic addition to a cholesterol scaffold, or hydrolytic removal therefrom, was expected to change the emission wavelength. To prepare them, sonochemically-derived ${ }^{13}$ 4-nitro-1,8-naphthalimides were reduced in $\sim 90 \%$ yield by hydrogenation over $\mathrm{Pd} / \mathrm{C}$ catalyst. The subsequent reactions of 1 with cholesteryl chloroformate were readily monitored by silica gel TLC, as the desired products $\mathbf{2}$ appear blue when visualized with a $365 \mathrm{~nm}$ UV lamp. Isolation of the conjugates required column chromatography to remove unreacted amines, which persisted after five days of heating in ethyl acetate at $55^{\circ} \mathrm{C}$. Proton NMR of purified $\mathbf{2 a}$ and $\mathbf{2 b}$ showed each to be a mixture of alkene isomers at C5-C6 and C4-C5. ${ }^{14}$ The latter, unnatural isomers presumably arise from deprotonation at the allylic $\mathrm{C} 4$ position during the lengthy reaction period. ${ }^{1} \mathrm{H}$ NMR was also used to confirm fluorophore attachment, with the $\mathrm{N} H$ resonances of the carbamate linkers of $\mathbf{2 a}$ and $\mathbf{2 b}$ appearing at $7.38 \mathrm{ppm}$ in $\mathrm{CDCl}_{3}$. The carbamates were found to be stable toward hydrolysis at $\mathrm{pH} 7.4$ and $37{ }^{\circ} \mathrm{C}$ for at least one week. 
<smiles>CCN1C(=O)c2cccc3c([N+](=O)[O-])ccc(c23)C1=O</smiles>

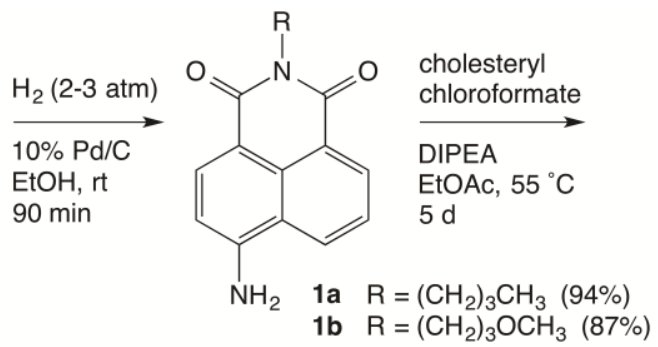

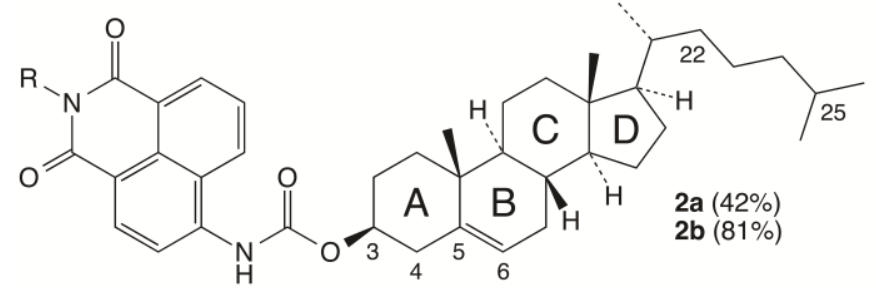

Scheme 1. Synthesis of cholesterol-naphthalimide conjugates. Products $\mathbf{2 a}$ and $\mathbf{2 b}$ are isolated as mixtures of alkene isomers at C5-C6 (shown) and C4-C5 that are inseparable by TLC or flash column chromatography.

\subsection{Spectroscopic behavior in organic and aqueous solution}

Electronic absorption and emission spectra were acquired in low- and high-polarity media (Table 1). Moving from dichloromethane to $0.10 \mathrm{M}$ aqueous phosphate buffer $(\mathrm{pH}=7.4)$, the longestwavelength absorptions for $\mathbf{2} \mathbf{a}$ and $\mathbf{2 b}(\sim 370 \mathrm{~nm})$ undergo modest red-shifts. The same trend is observed computationally. Time-dependent density functional theory (DFT) calculations ${ }^{15}$ upon a truncated model of $\mathbf{2 a}$, in which the cholesteryl moiety has been replaced with methyl, predict the HOMO $\rightarrow$ LUMO transition to occur at $369.3 \mathrm{~nm}$ in the gas phase, with an oscillator strength of 0.28 . With two explicit water molecules hydrogen-bonded to each of the imide $\mathrm{C}=\mathrm{O}$ groups, the calculated absorption appears at $374.8 \mathrm{~nm}$. The shifts in the emission bands are more pronounced (> $40 \mathrm{~nm}$ ), in accord with a high degree of charge separation in the excited state. ${ }^{11 \mathrm{c}}$ Other acylated 4-aminonaphthalimides have previously been found to emit in the 480-nm range in aqueous solution. ${ }^{11 \mathrm{~b}}$ 
Table 1. Photophysical Properties of Steroid-Fluorophore Conjugates ${ }^{a}$

\begin{tabular}{|c|c|c|c|c|c|}
\hline & $\begin{array}{l}\lambda_{\mathrm{abs}}, \mathrm{nm} \\
\left(\mathrm{CH}_{2} \mathrm{Cl}_{2}\right)\end{array}$ & $\begin{array}{c}\lambda_{\mathrm{abs}}, \mathrm{nm} \\
(\mathrm{aq} \cdot \text { buffer })^{b}\end{array}$ & $\begin{array}{c}\lambda_{\mathrm{em}}, \mathbf{n m} \\
\left(\mathrm{CH}_{2} \mathrm{Cl}_{2}\right)\end{array}$ & $\begin{array}{c}\lambda_{\mathrm{em}}, \mathrm{nm} \\
(\mathrm{aq} \cdot \mathrm{buffer})^{b}\end{array}$ & $\begin{array}{c}\lambda_{\mathrm{em}}, \mathrm{nm} \\
\text { (liposomes) }^{c}\end{array}$ \\
\hline $2 \mathbf{a}$ & 373 & 378 & $443\left(\Phi_{\mathrm{F}}=0.70\right)^{d}$ & 487 & 484 \\
\hline $2 b$ & 371 & 378 & $441\left(\Phi_{\mathrm{F}}=0.70\right)^{d}$ & 495 & 483 \\
\hline
\end{tabular}

${ }^{a}$ For all fluorescence measurements, $[2]=3.0 \times 10^{-6} \mathrm{M}, \lambda_{\mathrm{ex}}=375 \mathrm{~nm} .{ }^{b}\left[\mathrm{NaH}_{2} \mathrm{PO}_{4}\right]=0.023 \mathrm{M}$, $\left[\mathrm{Na}_{2} \mathrm{HPO}_{4}\right]=0.077 \mathrm{M}, \mathrm{pH}=7.4 .{ }^{c}$ Small unilamellar vesicles comprised of POPC and cholesterol (7:3, mol:mol), $[\mathrm{POPC}+$ cholesterol $]=2.9 \times 10^{-3} \mathrm{M}, 0.10 \mathrm{M}$ phosphate buffer. ${ }^{d}$ Relative to $7-$ amino-4-methylcoumarin $\left(\Phi_{\mathrm{F}}=0.63\right.$ in $\left.\mathrm{CH}_{3} \mathrm{CN}\right)$.

\subsection{Localization in liposomal model membranes}

To explore how the labeled steroids might interact with mammalian (host) cells, the fluorescence properties of $\mathbf{2}$ were also assessed in the presence of liposomal model membranes. Small unilamellar vesicles were constituted in $\mathrm{pH} 7.4$ phosphate buffer from 1-palmitoyl-2-oleoyl-snglycero-3-phosphocholine (POPC) and cholesterol, in a 7:3 molar ratio. Conjugate $\mathbf{2 a}$ or $\mathbf{2 b}$ was introduced to the gently stirring lipid suspension as a solution in DMSO-dioxane (1:1, v:v) such that the concentration of $\mathbf{2}$ was approximately one-thousandth of [POPC+cholesterol]. An emission spectrum was immediately acquired $\left(\lambda_{\mathrm{ex}}=375 \mathrm{~nm}, \lambda_{\mathrm{em}}=390-600 \mathrm{~nm}\right)$, and additional spectra were recorded at five-minute intervals until the integrated intensities became constant. Equilibrium was reached after about 15 minutes. Final emission intensities were higher than those found in plain buffer (Figure 1), but were still an order of magnitude lower than observed in dichloromethane. Thus, a significant fraction of the naphthalimide units are located outside the 
hydrophobic core of the lipid bilayer. Proton NMR data are consistent with tight binding of 2 to the membrane, despite the presence of conjugates with C4-C5 double bonds, which are known to render cholesterol less effective at membrane incorporation. ${ }^{14}$ Liposomes of POPC $(0.010 \mathrm{M})$ and $2 \mathbf{b}(0.0043 \mathrm{M})$ in pure $\mathrm{D}_{2} \mathrm{O}$ display only three broad ${ }^{1} \mathrm{H}$ NMR signals at $0.84,1.24$, and 3.19 ppm, all of which are assigned to $\mathrm{CH}_{\mathrm{n}}$ of the phospholipid. The absence of other peaks suggests that there is practically no free $\mathbf{2} \mathbf{b}$ present in the bulk solution.

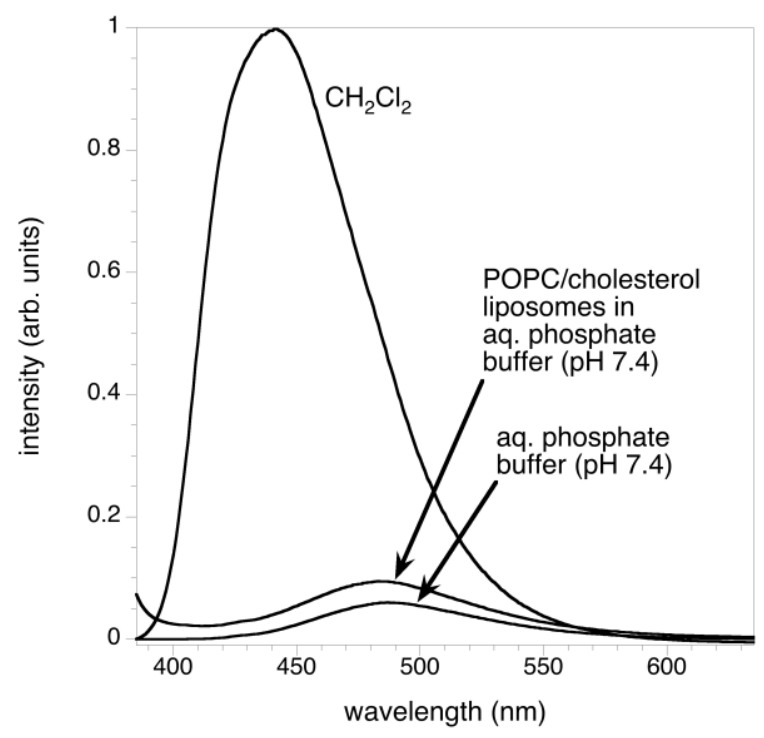

Figure 1. Emission spectra of compound 2a at a concentration of $3.0 \times 10^{-6} \mathrm{M}$ in different milieu. $\lambda_{\mathrm{ex}}=375 \mathrm{~nm}$.

Data from fluorescence titrations with acids show that the fluorophore of liposome-bound 2a retains some ability to report on the properties of the bulk aqueous environment. When $1 \mathrm{M}$ $\mathrm{HCl}$ was used to lower the $\mathrm{pH}$ of buffered POPC/cholesterol/2a suspensions from 7.1 to 3.0 , the emission intensity of $\mathbf{2 a}$ was unchanged (Figure 2). An equivalent $\mathrm{pH}$ drop brought about by glacial acetic acid caused an increase in fluorescence of about one-half. A relatively large 
volume of (weakly acidic) $\mathrm{CH}_{3} \mathrm{COOH}$ was required to bring the samples to $\mathrm{pH} 3.0$, and it is possible that $\mathbf{2 a}$ is responding to the presence of the lower-polarity solvent. As acetic acid is membrane-permeant in its undissociated, electrically neutral form, this effect should be observed whether the fluorophore is dangling outside of the bilayer or buried within it.

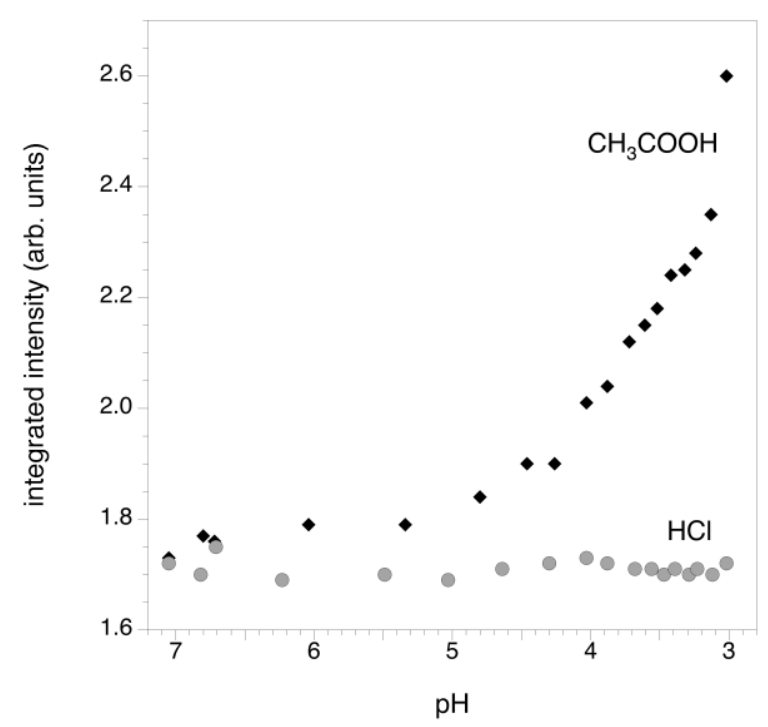

Figure 2. Fluorescence response of liposome-bound $\mathbf{2 a}$ to acetic and hydrochloric acids. [2a] $=$ $3.0 \times 10^{-6} \mathrm{M},[\mathrm{POPC}+$ cholesterol $]=2.9 \times 10^{-3} \mathrm{M}, 0.10 \mathrm{M}$ phosphate buffer.

In previous work with liposomes comprised of POPC and cholesterol (2:1, mol:mol), the long axis of the steroid was determined to be oriented approximately perpendicular to the bilayer plane, with limited steroid motion along this axis allowed at ambient temperature. ${ }^{16}$ Assuming that the cholesteryl portions of $\mathbf{2}$ anchor to liposomes in this typical manner, computational analyses were performed to determine if the fluorophores could fold over to reside within the hydrated glycerol/phosphocholine area region. This would be a favorable location-NMR studies with tryptophan and other aromatic compounds have shown that rigid heterocycles tend to seek out membrane interfaces. ${ }^{17}$ Among the many possible conformations of $\mathbf{2 a}$, at one 
extreme is an extended geometry with a distance between terminal C's of $28.5 \AA$ (Figure 3). It would expose the nonpolar $N$-butyl group of the naphthalimide to the external aqueous solution. In contrast, in a bent geometry brought about by rotation at the amide bond of the linker unit, the fluorophore could lie within the phospholipid headgroup area. The total energy of the bent form is predicted to be $2.1 \mathrm{kcal} / \mathrm{mol}$ higher than the extended conformation, a difference that could be easily overcome at $37^{\circ} \mathrm{C}$.

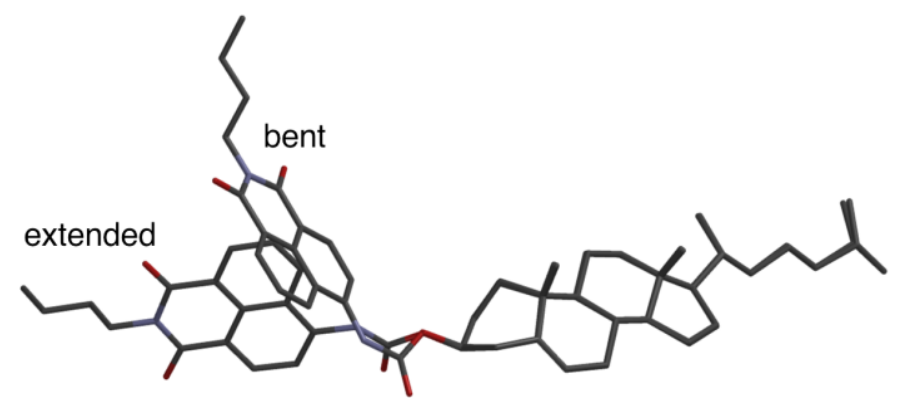

Figure 3. DFT-optimized structures of 2a in a solvent dielectric corresponding to 1-octanol. Ring atoms of the cholesteryl units were overlaid to highlight differences in positions of the fluorophores. For clarity, hydrogen atoms are not shown.

\subsection{Bacterial uptake}

To determine whether bacteria with a dedicated steroid recognition system would import modified cholesterols 2, Mycobacterium smegmatis mc2 $155^{18}$ was grown to mid-exponential phase and transferred to a nutrient-poor medium ${ }^{2 \mathrm{a}}$ supplemented with the conjugates at concentrations of $1.15 \mathrm{mM}$. M. smegmatis shares $70 \%$ genetic identity with M. tuberculosis, and includes the mce4 operon that encodes a steroid transporter, but is considered non-pathogenic and features a significantly shorter replication time. Samples of bacterial cultures were harvested at 48,72 , and 96 hours, the aqueous components removed, and the remaining cellular material 
extracted with $\mathrm{CH}_{2} \mathrm{Cl}_{2}-\mathrm{CH}_{3} \mathrm{OH}(2: 1, \mathrm{v}: \mathrm{v})$ to isolate the total lipid fraction. The solutions so obtained were evaporated, and the residue analyzed by reversed-phase HPLC using a C18 column with water-isopropyl alcohol elution. Absorbance was simultaneously monitored at 375 $\mathrm{nm}$ (to detect compounds with an intact naphthalimide-carbamate bond) and at $430 \mathrm{~nm}$ (to detect liberated napthalimides $\mathbf{1}$ ). Unmodified $\mathbf{2 a}$ and $\mathbf{2 b}$ were present in the bacterial membrane extracts from all three days, as judged by comparison of retention times to original samples, and by the appearance of peaks corresponding to $[2+\mathrm{H}]^{+}$and/or $[2+\mathrm{Na}]^{+}$in electrospray ionization mass spectra. No evidence of the unconjugated fluorophores was found. The aqueous culture media were similarly devoid of unconjugated fluorophores according to ESI-MS. Thus, $M$. smegmatis does not promote hydrolysis of the linker units under the conditions employed. The cultures from above were also used to assess bacterial viability in the presence of $\mathbf{1 a}$, 1b, 2a, and $\mathbf{2 b}$. Colony-forming units (CFU) were counted at 24-hour intervals for a period of seven days (Figure 4). The bacterial samples supplemented with unmodified cholesterol showed little difference in growth from the steroid-free controls for most of the assay period. However, after 48 hours, the cultures containing $\mathbf{1 a}$ and $\mathbf{1 b}$ had significantly lower concentrations of viable cells than those grown with natural cholesterol, while the conjugates had a proliferative effect. The mechanism(s) of growth enhancement by $\mathbf{2} \mathbf{a}$ and $\mathbf{2 b}$ are unknown. If the increase is caused by bacterial utilization of both the steroid and naphthalimide portions as carbon sources, then the fluorescent tags are likely processed differently than the free fluorophores, since there is no delayed detrimental effect observed within the time period of this assay. Alternatively, the polar functional groups in $\mathbf{2}$ may enhance the water solubility of the conjugates, facilitating their diffusion through the aqueous culture to the bacteria for subsequent catabolism. A search for metabolites of $\mathbf{2} \mathbf{a}$ and $\mathbf{2} \mathbf{b}$ within the culture media is underway to determine if D-ring side-chain 
degradation of these molecules has indeed occured. ${ }^{19}$

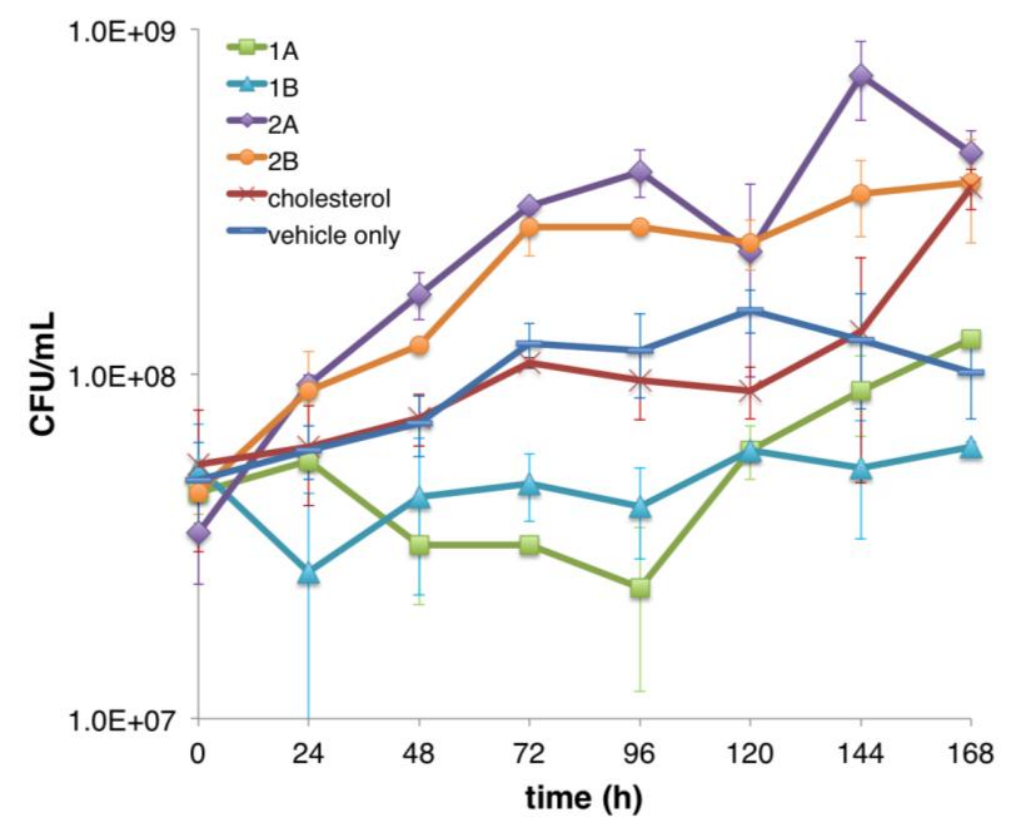

Figure 4. Growth of M. smegmatis mc2 155 in defined minimal medium supplemented with ethanol/Tyloxapol vehicle and the compounds indicated. $P$ values $\leq 0.01$ were deemed significant as assessed by Student's 2-tailed T-test. Significant differences: 1a, 48, 72, and 96 h; 1b, 24, 72, and 168 h; 2a, 48, 96, and 144 h; 2b, 48 and 120 h.

\subsection{Conclusions}

Appending a naphthalimide reporter group to the 3-position of cholesterol does not prevent its localization within synthetic or mycobacterial membranes. The fluorophore remains outside of the bilayer core. These findings support the proposed utility of the conjugates as tools for the in vivo tracking of cholesterol uptake in bacteria. Additionally, although the fluorophores themselves are toxic to prokaryotic cells, the present conjugates containing them are not. This 
suggests that the toxicity of naphthalimide compounds observed in previous studies may depend upon interactions associated with the $-\mathrm{NH}_{2}$ side group, or upon the mechanisms of uptake and processing.

\section{Experimental Section}

\subsection{Synthesis of (3S,8S,10R,13R,14S,17R)-10,13-dimethyl-17-((R)-6-methylheptan-2-yl)-}

2,3,4,7,8,9,10,11,12,13,14,15,16,17-tetradecahydro-1H-cyclopenta[a]phenanthren-3-yl 2-butyl1,3-dioxo-2,3-dihydro-1H-benzo[de]isoquinolin-6-ylcarbamate (2a). Naphthalimide $1 \mathrm{a}$ (63 mg, $0.23 \mathrm{mmol})$ and cholesteryl chloroformate $(164 \mathrm{mg}, 0.37 \mathrm{mmol})$ were combined in $10 \mathrm{~mL}$ of dry stirring ethyl acetate under nitrogen. The yellow-green solution was treated with $\mathrm{N}, \mathrm{N}$ diisopropylethylamine ( $44 \mu \mathrm{L}, 0.25 \mathrm{mmol}$ ), a reflux condenser was fitted to the flask, and the mixture was heated to $55^{\circ} \mathrm{C}$ with a preheated oil bath. Progress of the reaction was monitored by thin-layer chromatography using $\mathrm{CH}_{2} \mathrm{Cl}_{2}$ as the mobile phase. After $72 \mathrm{~h}, \mathrm{TLC}$ analysis showed two spots that fluoresced under UV irradiation (365 nm): starting material 1a (yellow-green) and a faster compound (blue, $R_{\mathrm{f}}=0.12$ ). An additional $41 \mathrm{mg}$ of cholesteryl chloroformate was added to the reaction, and heating/stirring was continued for $48 \mathrm{~h}$. Upon cooling to room temperature, the mixture became faintly cloudy. Volatile components were removed via rotary evaporation to afford a yellow solid. The residue was purified by flash column chromatography on silica gel using dichloromethane as the eluent. A very fast-moving, poorly-emissive band of material was discarded, then bright fluorescent blue fractions containing desired product $\mathbf{2 a}$ were combined and evaporated to a thick yellow film (65 mg, $42 \%) .{ }^{1} \mathrm{H}$ NMR $\left(\mathrm{CDCl}_{3}\right) \delta 0.70(\mathrm{~s}, 6 \mathrm{H}), 0.87-2.01$ $(\mathrm{m}, 36 \mathrm{H}), 2.50(\mathrm{~m}, 6 \mathrm{H}), 3.55(\mathrm{~m}$, fractional integration, C3-H in C5-C6 alkene isomer), $4.19(\mathrm{t}$, 2H), 4.74 ( $\mathrm{m}$, fractional integration, $\mathrm{C} 3-\mathrm{H}$ in $\mathrm{C} 4-\mathrm{C} 5$ alkene isomer), 5.38 (d, fractional 
integration, C5-C6 alkene), 5.47 (d, fractional integration, C4-C5 alkene), 7.38 (s, 1H), 7.79 (t, $1 \mathrm{H}), 8.21(\mathrm{~d}, 1 \mathrm{H}), 8.42(\mathrm{~d}, 1 \mathrm{H}), 8.62-8.67(\mathrm{~m}, 2 \mathrm{H}) ;{ }^{13} \mathrm{C} \mathrm{NMR}\left(\mathrm{CDCl}_{3}\right) \delta 11.86,13.85,18.72$, $19.40,20.40,21.06,22.56,22.82,23.84,28.01,28.24,28.38,29.70,30.22,31.89,31.92,35.80$, $36.19,36.60,37.07,38.75,38.77,39.19,39.52,39.75,42.32,50.02,56.14,56.70,74.12,74.23$, $116.53,117.63,120.66,122.26,123.16,123.16,123.49,124.50,125.98,126.48,126.53,128.96$, $131.19,132.59,139.27,140.06,145.30,145.60,152.71,155.42,155.58,163.71,164.20,164.58$. HRMS (ESI) calcd for $\mathrm{C}_{44} \mathrm{H}_{60} \mathrm{~N}_{2} \mathrm{O}_{4}(\mathrm{M}+\mathrm{H})^{+}$681.4631, found 681.4152.

\subsection{Synthesis of (3S,8S,10R,13R,14S,17R)-10,13-dimethyl-17-((R)-6-methylheptan-2-yl)- 2,3,4,7,8,9,10,11,12,13,14,15,16,17-tetradecahydro-1H-cyclopenta[a]phenanthren-3-yl 2-(3- methoxypropyl)-1,3-dioxo-2,3-dihydro-1H-benzo[de]isoquinolin-6-ylcarbamate (2b).}

Conjugate $\mathbf{2 b}$ was synthesized in a manner similar to that of $\mathbf{2 a}$, by combining $50 \mathrm{mg}$ of naphthalimide $\mathbf{1 b}(0.18 \mathrm{mmol}), 130 \mathrm{mg}$ of cholesteryl chloroformate $(0.28 \mathrm{mmol})$, and $35 \mu \mathrm{L}$ of DIPEA in $8 \mathrm{~mL}$ of ethyl acetate at $55^{\circ} \mathrm{C}$. Additional cholesteryl chloroformate was not added. After $5 \mathrm{~d}$, the mixture deposited a yellow precipitate upon cooling. The suspension was evaporated under vacuum, and the resultant gold solid purified by flash column chromatography using $\mathrm{CH}_{2} \mathrm{Cl}_{2}-\mathrm{CH}_{3} \mathrm{OH}(20: 1, \mathrm{v}: \mathrm{v})$ as the eluent. Intensely fluorescent blue fractions were evaporated to afford the desired product as a lemon-yellow solid (99 mg, 81\%). Mp 136-148 ${ }^{\circ} \mathrm{C}$; ${ }^{1} \mathrm{H} \mathrm{NMR}\left(\mathrm{CDCl}_{3}\right) \delta 0.71(\mathrm{~s}, 6 \mathrm{H}), 0.90-1.56(\mathrm{~m}, 20 \mathrm{H}), 1.86(\mathrm{~m}, 5 \mathrm{H}), 2.05(\mathrm{~m}, 6 \mathrm{H}), 2.30(\mathrm{~m}, 4 \mathrm{H})$, $2.51(\mathrm{~m}, 2 \mathrm{H}), 3.36(\mathrm{~s}, 3 \mathrm{H}), 3.55(\mathrm{t}, 2 \mathrm{H}), 4.30(\mathrm{t}, 2 \mathrm{H}), 4.73(\mathrm{~m}$, fractional integration, $\mathrm{C} 3-\mathrm{H}$ in C4C5 alkene isomer), 5.38 (d, fractional integration, C5-C6 alkene), 5.46 (d, fractional integration, C4-C5 alkene), $7.38(\mathrm{~s}, 1 \mathrm{H}), 7.80(\mathrm{t}, 1 \mathrm{H}), 8.22(\mathrm{~d}, 1 \mathrm{H}), 8.44(\mathrm{~d}, 1 \mathrm{H}), 8.62(\mathrm{~d}, 1 \mathrm{H}), 8.66(\mathrm{~d}, 1 \mathrm{H})$;

${ }^{13} \mathrm{C} \mathrm{NMR}\left(\mathrm{CDCl}_{3}\right) \delta 11.87,18.73,19.41,21.09,22.57,22.83,23.84,24.30,28.02,28.24,31.64$, 
$31.91,35.80,36.20,36.59,36.94,37.26,37.87,38.37,39.52,39.79,42.33,50.01,50.13,56.16$, $56.69,56.77,58.50,70.65,71.82,116.47,117.52,121.72,122.79,123.18,123.40,126.00$, $126.49,128.95,131.23,132.63,139.25,139.30,140.76,152.70,163.69,164.18$. HRMS (ESI) calcd for $\mathrm{C}_{44} \mathrm{H}_{60} \mathrm{~N}_{2} \mathrm{O}_{5}(\mathrm{M}+\mathrm{H})^{+}$697.9810, found 697.9772 .

3.3 Preparation of Liposomes for Fluorescence Spectroscopy. POPC (22.8 mg, $\left.3.00 \times 10^{-5} \mathrm{~mol}\right)$ and cholesterol $\left(5.0 \mathrm{mg}, 1.3 \times 10^{-5} \mathrm{~mol}\right)$ were dissolved in $10 \mathrm{~mL}$ of $\mathrm{CH}_{2} \mathrm{Cl}_{2}$-cyclohexane (1:1, vol:vol) with gentle swirling. The solvents were removed via rotatory evaporation using a room temperature water bath, and the resultant lipid film was dried on a high vacuum manifold for at least one hour. Fifteen $\mathrm{mL}$ of aqueous phosphate buffer $\left(\left[\mathrm{NaH}_{2} \mathrm{PO}_{4}\right]=0.023 \mathrm{M},\left[\mathrm{Na}_{2} \mathrm{HPO}_{4}\right]=\right.$ $0.077 \mathrm{M}, \mathrm{pH}=7.4$ ) was added, the flask was capped and agitated with a vortex mixer for $5 \mathrm{~min}$, then was magnetically stirred for one hour. To obtain unilamellar vesicles, the mixture was subjected to three freeze-thaw cycles using liquid nitrogen and a lukewarm water bath. Onemilliliter aliquots of the thawed solution were extruded at least 15 times through a $0.1 \mu \mathrm{m}$ polycarbonate membrane to afford a faintly iridescent blue suspension. For fluorescence measurements, $3.0 \mathrm{~mL}$ of the extruded liposome mixture was added to a quartz cuvette containing a small stir bar. A baseline spectrum was obtained, then $\mathbf{2 a}$ or $\mathbf{2 b}$ was introduced from a syringe as a millimolar solution in spectrophotometric grade DMSO or DMSO-dioxane (1:1, v:v). The 2 :total lipid ratio was typically 1:1000 on a molar basis.

3.4 Growth of M. smegmatis in the Presence of 1 and 2. M. smegmatis mc2 155 was grown on LB agar. An isolated colony of bacteria was collected from an agar plate and suspended in $75 \mu \mathrm{L}$ of sterile $7 \mathrm{H} 9$ medium. To prepare the initial culture, $250 \mathrm{~mL}$ of sterile $7 \mathrm{H} 9$ was added to a 500 
$\mathrm{mL}$ flask and then inoculated with $25 \mu \mathrm{L}$ of the previously prepared bacterial suspension. Bacterial growth was monitored using $\mathrm{OD}_{600}$ measurements. Once mid-exponential phase had been reached $\left(\mathrm{OD}_{600} \approx 0.5\right)$, the $7 \mathrm{H} 9$ culture was divided into several sterilized centrifuge tubes, with each tube receiving $25 \mathrm{~mL}$ of culture. The tubes were centrifuged for 15 minutes at 10,000 rpm. The supernatants were removed, the bacterial pellets were treated with $10 \mathrm{~mL}$ of sterile phosphate-buffered saline (PBS), and the tubes centrifuged again. The supernatants were again discarded and the pellets given a final PBS wash. The pellets were then suspended in $25 \mathrm{~mL}$ of defined minimal media, ${ }^{2 \mathrm{a}}$ prepared by dissolving asparagine $(0.5 \mathrm{~g} / \mathrm{L}), \mathrm{KH}_{2} \mathrm{PO}_{4}(1.0 \mathrm{~g} / \mathrm{L})$, $\mathrm{Na}_{2} \mathrm{HPO}_{4}(2.5 \mathrm{~g} / \mathrm{L}), \mathrm{MgSO}_{4}(0.22 \mathrm{~g} / \mathrm{L}), \mathrm{CaCl}_{2}(0.0005 \mathrm{~g} / \mathrm{L}), \mathrm{ZnSO}_{4}(0.0001 \mathrm{~g} / \mathrm{L})$ and ferric citrate $(100 \mu \mathrm{L} / \mathrm{L})$ into distilled deionized water and then sterilizing the solution using a $0.22 \mu \mathrm{m}$ filter.

Test compounds (1a, $7.7 \mathrm{mg}$; 1b, $8.2 \mathrm{mg}$; 2a, $19.6 \mathrm{mg}$; 2b, $20.1 \mathrm{mg}$; cholesterol, $11.1 \mathrm{mg}$ ) were each suspended in $192 \mu \mathrm{L}$ of $95 \%$ ethanol and $96 \mu \mathrm{L}$ of Tyloxapol in a small sterile tube. To better solubilize the compounds, the tubes were heated in a water bath at $55^{\circ} \mathrm{C}$ for $5-10$ minutes and were then agitated with a vortex mixer. The contents were separately transferred into the bacterial suspensions from above, and the mixtures thoroughly agitated. The resulting 25 $\mathrm{mL}$ volumes of culture were divided into $4 \mathrm{~mL}$ portions among six culture tubes (for counts of colony-forming units (CFU) and HPLC analyses of bacterial uptake of 2). A $200 \mu \mathrm{L}$ aliquot was immediately removed from each tube, serially 10-fold diluted, and then plated on LB agar to obtain an initial CFU count. The culture tubes were placed in a shaker at $37^{\circ} \mathrm{C}$ and viability was checked by plating serial 10-fold dilutions at 8 -hour intervals until 48 hours had passed, then every 24 hours thereafter. 
3.5 Extraction of 2 from Bacterial Membranes and HPLC Analysis. An aliquot (0.5 mL) was transferred from each culture tube described above into a sterile centrifuge tube. The samples were spun at 13,300 rpm for five minutes. The resulting supernatants were typically discarded (but could be stored at $-20^{\circ} \mathrm{C}$ for analysis of polar compounds). The remaining cell pellets were washed twice with $1 \mathrm{~mL}$ portions of PBS, discarding the liquid each time, and were then stored in small sterile tubes at $-20^{\circ} \mathrm{C}$. This process was repeated at 48,72 , and 96 hours. A published method $^{20}$ was adopted for extraction of the total lipid fraction of $M$. smegmatis. The previously collected cell pellets were thawed and a small stir bar was added to each tube along with $0.5 \mathrm{~mL}$ of $\mathrm{CH}_{2} \mathrm{Cl}_{2}-\mathrm{CH}_{3} \mathrm{OH}(2: 1, \mathrm{v}: \mathrm{v})$. The samples were stirred while tightly capped for 24 hours, after which the stir bars were removed and the samples were centrifuged for five minutes to pellet any remaining solids. The organic solvents were carefully transferred into clean uncapped tubes, which were left overnight to allow for evaporation.

Once dried, the remaining lipid films were dissolved in $1 \mathrm{~mL}$ of HPLC-grade water/2propanol (1:1, v:v) for introduction into the instrument. A 250 mm-long C18 column with 4.6 $\mathrm{mm}$ inner diameter was used. The mobile phase consisted of water and 2-propanol with $0.1 \%$ trifluoroacetic acid, at a flow rate of $1.0 \mathrm{~mL} / \mathrm{min}$. UV-vis detection was set for 375 and $430 \mathrm{~nm}$. The column was conditioned by running a mixture of water/2-propanol (4:1, v:v) for two minutes, the sample was injected over one minute, then the following eluent composition program was executed: (1) isochratic 4:1 water/2-propanol for $5 \mathrm{~min}$; (2) gradient to 1:4 water/2propanol over $10 \mathrm{~min}$; (3) isochratic 1:4 water/2-propanol for $10 \mathrm{~min}$; (4) gradient to 4:1 water/2propanol over 5 min. Compounds $\mathbf{2 a}$ and $\mathbf{2 b}$ had retention times of $28.7 \mathrm{~min}$ and $27.5 \mathrm{~min}$, respectively. Their identities were confirmed by comparison with HPLC runs of pure samples, and by ESI-QToF mass spectrometry. 
3.6 Computational methods. The density functional software package DMol3 was used for all calculations. The Becke-Tsuneda-Hirao gradient-corrected functional was used along with double numerical plus polarization basis sets, a $20 \mathrm{bohr}$ cutoff, fine integration grid, and scalar relativistic corrections. Default convergence criteria of $10^{-6}$ Hartrees for the SCF and $10^{-3}$ Hartrees/Bohr for the gradient in geometry optimizations were employed.

\section{Acknowledgments}

A.L.S. acknowledges the ECU CACS and the NSF (CNS-0619285). Purchase of NMR and mass spectrometers was made possible by the NSF (CRIF-0077988 and MRI-0521228, respectively). A.N.W. was supported a Burroughs-Wellcome Fellowship for 2013-2014. The authors thank Sarah R. Marshall for assistance with liposome preparations and NMR, and Amanda L. Morgan for contributing to synthesis.

\section{References}

1. Vromman, F.; Subtil, A. Curr. Opin. Microbiol. 2014, 17, 38-45.

2. (a) Pandey, A. K.; Sassetti, C. M. Proc. Natl. Acad. Sci. USA 2008, 105, 4376-4380. (b) van der Geize, R.; Yam, K.; Heuser, T.; Wilbrink, M. H.; Hara, H.; Anderton, M. C.; Sim, E.; Dijkhuizen; , L.; Davies, J. E.; Mohn, W. W.; Eltis, L. D. Proc. Natl. Acad. Sci. USA 2007, 104, 1947-1952.

3. (a) Wipperman, M. F.; Sampson, N. S.; Thomas, S. T. Crit. Rev. Biochem. Mol. Biol. 2014, 49, 269-293. (b) Ouellet, H.; Johnston, J. B.; Ortiz de Montellano, P. R. Trends Microbiol. 2011, 19, 530-539. 
4. Mohn, W. W.; van der Geize, R.; Stewart, G. R.; Okamoto, S.; Liu, J.; Dijkhuizen, L.;

Eltis, L. D. J. Biol. Chem. 2008, 283, 35368-35374.

5. (a) Cao, X.; Mi, T.; Li, L.; Vermeer, M. A.; Zhang, C.; Huang, N.; Manoj, J. K.

Biomed. Chromatogr. 2013, 27, 910-915. (b) Faletrov, Y. V.; Frolova, N. S.; Hlushko,

H. V.; Rudaya, E. V.; Edimecheva, I. P.; Mauersberger, S.; Shkumatov, V. M. FEBS J. 2013, 280, 3109-3119.

6. (a) Carter Ramirez, D. M.; Ogilvie, W. W.; Johnston, L. J. Biochem. Biophys. Acta 2010, 558-568. (b) Combrink, K. D.; Denton, D. A.; Harran, S.; Ma, Z.; Chapo, K.; Yan, D.; Bonventre, E.; Roche, E. D.; Doyle, T. B.; Robertson, G. T.; Lynch, A. S. Bioorg. Med. Chem. Lett. 2007, 17, 522-526.

7. (a) Shrivastava, S.; Haldar, S.; Gimpl, G.; Chattopadhyay, A. J. Phys. Chem. B 2009, 113, 4475-4481. (b) Tomas, S.; Milanesi, L. J. Am. Chem. Soc. 2009, 131, 6618-6623.

8. Bhatti, M.; McHugh, T. D.; Milanesi, L.; Tomas, S. Chem. Commun. 2014, 50, 76497651.

9. Peters, A. T.; Bide, M. J. Dyes Pigments 1985, 6, 349-375.

10. (a) El-Azab, A. S.; Alanazi, A. M.; Abdel-Aziz, N. I.; Al-Suwaidan, I. A.; El-Sayed, M. A. A.; El-Sherbeny, M. A.; Abdel-Aziz, A. A.-M. Med. Chem. Res. 2013, 22, 23602375. (b) de la Fuente, R.; Sonawane, N. D.; Arumainayagam, D.; Verkman, A. S. Br. J. Pharmacol. 2006, 149, 551-559.

11. (a) Veale, E. B.; Kitchen, J. A.; Gunnlaugson, T. Supramol. Chem. 2013, 25, 101-108. (b) Xu, Z.; Baek, K.-H.; Kim, H. N.; Cui, J.; Qian, X.; Spring, D. R.; Shin, I.; Yoon, J. J. Am. Chem. Soc. 2010, 132, 601-610. (c) Duke, R. M.; Veale, E. B.; Pfeffer, F. M.; Kruger, P. E.; Gunnlaugson, T. Chem. Soc. Rev. 2010, 39, 3936-3953. (d) Cui, D.; 
Qian, X.; Liu, F.; Zhang, R. Org. Lett. 2004, 6, 2757-2760. (e) Grabchev, I.; Qian, X.;

Bojinov, V.; Zhang, W. Polymer 2002, 43, 5731-5736.

12. (a) Nepras, M.; Almonasy, N.; Bures, F.; Kulhánek, J.; Dvorák, M.; Michl, M. Dyes Pigments 2011, 91, 466-473. (b) Barsu, C.; Cheaib, R.; Chambert, S.; Queneau, Y.; Maury, O.; Cottet, D.; Wege, H.; Douady, J.; Bretonnière, Y.; Andraud, C. Org. Biomol. Chem. 2010, 8, 142-150.

13. Triboni, E.; Filho, P.; Berlinck, R.; Politi, M. Synth. Commun. 2004, 34, 1989-1999.

14. Ranadive, G. N.; Lala, A. K. Biochemistry 1987, 26, 2426-2431.

15. (a) Delley, B. Int. J. Quantum Chem. 1998, 69, 423-433. (b) Tsuneda, T.; Hirao, K. Chem. Phys. Lett. 1997, 268, 510-520. (c) Klamt, A.; Schueuermann, G. J. Chem. Soc., Perkin Trans. 2 1993, 799-805. (d) Delley, B. J. Chem. Phys. 1990, 92, 508-517. (e) Becke, A. D. J. Chem. Phys. 1988, 88, 1053-1062.

16. Aussenac, F.; Tavares, M.; Dufourc, E. J. Biochemistry 2003, 42, 1383-1390.

17. Yau, W.-M.; Wimley, W. C.; Gawrisch, K.; White, S. H. Biochemistry 1998, 37, 14713-14718.

18. (a) Uhía, I.; Galán, B.; Kendall, S. L.; Stoker, N. G.; García, J. L. Environ. Microbiol. Rep. 2012, 4, 168-182. (b) Brzostek, A.; Sliwinski, T.; Rumijowska-Galewicz, A.; Korycka-Machala, M.; Dziadek, J. Microbiology 2005, 151, 2393-2402.

19. Steroid side-chain processing by mycobacteria can take place without prior oxidation at the A-ring (i.e., an -OH group at position 3 of the tetracyclic core is not essential for catabolism). See: (a) Lu, R.; Schmitz, W.; Sampson, N. S. Biochemistry 2015, 54, 5669-5672. (b) Frank, D. J.; Madrona, Y.; Ortiz de Montellano, P. R. J. Biol. Chem. 2014, 289, 30417-30425. 
20. Layre, E.; Sweet, L.; Hong, S.; Madigan, C. A.; Desjardins, D.; Young, D. C.; Cheng, T. Y.; Annand, J. W.; Kim, K.; Shamputa, I. C.; et al. Chem. Biol. 2011, 18, 1537-1549. 
Graphical Abstract

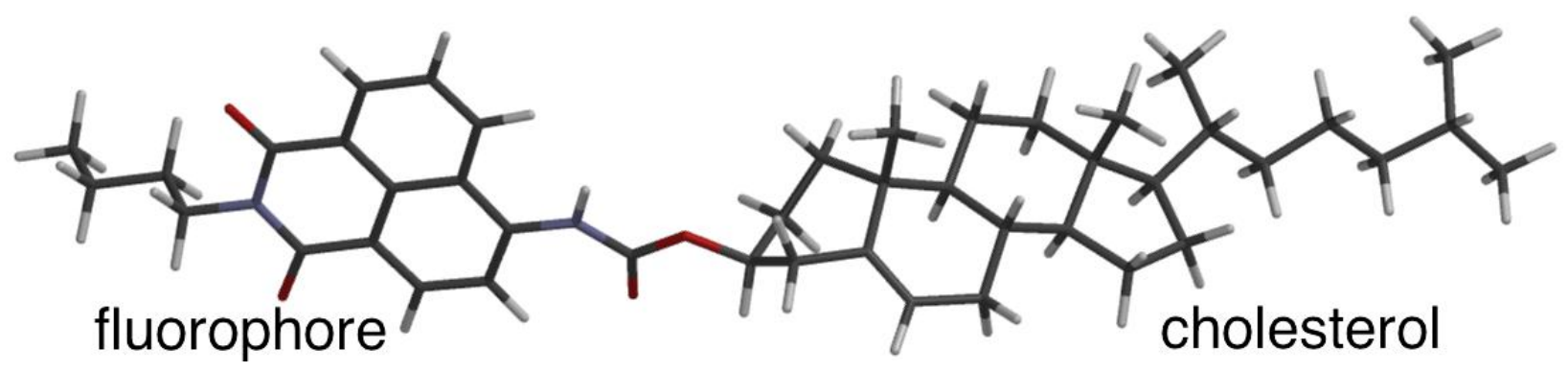

